\title{
ANÁLISIS CRÍTICO DEL PROYECTO DE LEY DE CREACIÓN DE LAS SOCIEDADES POR ACCIONES SIMPLIFICADAS*
}

Martín E. Abdala**

Fecha de recepción: 14 de febrero de 2017

Fecha de evaluación: 14 de diciembre de 2017

Fecha de aprobación: 22 de diciembre de 2017

Artículo de reflexión

DOI: http://dx.doi.org/10.18359/prole.3001

Forma de citación: Abdala, M. E. (2018). Análisis crítico del proyecto de ley de creación de las sociedades por acciones simplificadas. Revista Prolegómenos Derechos y Valores, 21, 41, 163-177. DOI: http://dx.doi.org/10.18359/prole.3001

\section{RESUMEN}

En el poder legislativo argentino se debate la sanción de una ley que crea las sociedades por acciones simplificadas. Se trata de un nuevo tipo de sociedad que, en nuestra opinión de manera errada, se propone crear, mediante una ley independiente y separada de la que regula las demás sociedades, es decir, la ley general de sociedades. La nueva sociedad se caracteriza porque su constitución e inscripción tienen mínimas exigencias (puede ser unipersonal, los capitales mínimos requeridos son exiguos, etc.), porque se aspira a que tenga una estructura de funcionamiento sencilla y dinámica y porque la responsabilidad de los socios está limitada a sus aportes. El objetivo del proyecto es plausible, pero acusa una pluralidad de defectos entre los que, uno de los más importantes, es que el propio proyecto incumple la promesa de simplicidad y propone una regulación alambicada, compleja y rebosante de diferentes aspectos del nuevo tipo societario.

\section{Palabras clave:}

Sociedades, sociedades por acciones, sociedades simples, tipos societarios, emprendedores.

Este trabajo pertenece a un proyecto de investigación promovido por el Conicet, Argentina.

** Doctor en Derecho por la Universidad de Colonia (Colonia, Alemania). Profesor asociado de Derecho Societario de la Universidad Nacional de Tucumán (Tucumán, Argentina). Correo electrónico: martinabdala@arnet.com.ar 


\title{
CRITIC ANALYSIS OVER THE SIMPLIFIED JOINT STOCK COMPANIES CREATION DRAFT BILL
}

\begin{abstract}
SUMMARY
Within the Argentinian legislative branch, it is discussed the promulgation of a bill that creates the simplified joint stock companies. This is about a new sort of company that in our thinking, it is mistaken to create both an independent and separated law from the one that regulates the remaining sort of companies, the Companies General Law. The new company is characterized by its formation and registration minimum requirements (it might be a single member company, the minimum required equity is meager, etc.). This as a result of its expectation to have a dynamic and simple functioning structure. Moreover, the shareholders liability is expected to be limited to the value of their equity. The draft is plausible, nevertheless, it brings a plurality of defects being one of the most relevant its failure to create simplicity by proposing a convoluted, complex and brimming set of different features of the new kind of company.
\end{abstract}

\section{Keywords:}

Companies, joint-stock company, civil partnership, type of company, entrepreneurs.

\section{ANÁLISE CRÍTICA DO PROJETO DA LEI PARA A CRIAÇÃO DAS EMPRESAS POR AÇÕES SIMPLIFICADAS}

\section{RESUMO}

No poder legislativo argentino é debatida a sanção de uma lei que cria as sociedades por ações simplificadas. Trata-se de um novo tipo de sociedade que, em nossa opinião de maneira errada, propõe-se criar, por meio de uma lei independente e separada da que regula outras sociedades, ou seja, a lei geral das sociedades. A nova empresa é caracterizada porque a sua constituição e registro tem requisitos mínimos (pode ser unipessoal, os requisitos de capital mínimo são escassos, etc.), porque se espera que tenha uma estrutura operacional simples e dinâmica e porque a responsabilidade dos parceiros é limitada a suas contribuições. O objetivo do projeto é plausível, mas acusa uma pluralidade de defeitos entre os quais, um dos mais importantes, é que o próprio projeto viola a promessa de simplicidade e propõe uma regulação arrebicada, complexa e transbordante de diferentes aspectos do novo tipo de sociedade.

\section{Palavras chave:}

Sociedade, sociedade por ações, sociedade simples, tipos de sociedades, empreendedores.

\section{Introducción}

El 2 de septiembre de 2016 se presentó en la Cámara de Diputados de la Nación un proyecto de ley intitulado "Marco legal favoreciendo la creación de nuevas empresas en la República Argentina y su expansión internacional. Creación del registro de instituciones de capital emprendedor", al que se le dio publicidad y difusión periodística con el nombre de "ley de emprendedores".

1 El proyecto fue enviado por el Poder Ejecutivo Nacional, con la firma de los ministros de Producción y de Hacienda y de Finanzas Públicas, sancionado el 16 de noviembre de 2016 por la Cámara de Diputados y remitido a la Cámara de Senadores, donde actualmente está en trámite parlamentario, con dictamen favorable de la 
El objetivo de la norma, expresado en su exposición de motivos, es brindar un marco legal que favorezca la creación de nuevas empresas y que promueva la "actividad emprendedora" en Argentina.

El proyecto tiene dos secciones: en la primera se regulan medidas de apoyo a la actividad de los emprendedores (por ejemplo la reducción de impuestos, la creación de un fondo fiduciario para el desarrollo de capital emprendedor, la regulación de un sistema de financiamiento colectivo -crowdfunding-, etc.) y en la segunda se legisla sobre un nuevo tipo societario: la sociedad por acciones simplificada. Sobre esta última sección concentraremos nuestra atención en este artículo.

\section{A. Peculiaridades del proyecto}

\section{La creación de un nuevo tipo y su inserción en el ordenamiento societario}

Como referimos en el acápite anterior, el proyecto plantea incorporar al ordenamiento jurídico societario argentino un nuevo tipo de sociedad que se denomina "sociedad por acciones simplificada", que regulará esa ley y, supletoriamente, la Ley General de Sociedades.

La norma declama que su principal objetivo es ofrecer a la comunidad y, en especial a los empresarios y emprendedores, la posibilidad de organizar una empresa con una estructura societaria simple (que incluso puede ser unipersonal), de muy bajo costo, de rápida generación o puesta en marcha y de funcionamiento simplificado $y$ desburocratizado.

En líneas generales, el proyecto es una idea valiosa que satisface un viejo reclamo del empresariado argentino, apoyado por un importante sector de la doctrina vernácula que, desde hace ya tiempo, propone autorizar la creación e implementación

Comisión de Economías Regionales, Economía Social, Micro, Pequeña y Mediana Empresa y de la Comisión de Presupuesto y Hacienda. de sociedades unipersonales que permitan no solo organizar empresas individuales, sino también producir patrimonios de afectación.

En ese orden de ideas, el proyecto se aparta de la línea de pensamiento, que podemos calificar como ortodoxa, de un significativo sector de los autores nacionales que, so pretexto de dar garantías a la comunidad (que a la postre resultan por lo corriente inútiles), sugiere ralentizar o lisa y llanam amiento jurídico societario y, por lo tanto, no debería sancionarse en un cuerpo normativo independiente, con permanentes remisiones, sino mediante una adecuada modificación de la Ley General de Sociedades e inclusión en ella del nuevo tipo.

El yerro que señalamos es de fácil solución y se logra modificando el proyecto y cambiando su objetivo de modo tal que, en lugar de autorizar una nueva forma de sociedad con pretensiones de independencia con respecto a las previstas en la Ley General de Sociedades, se circunscriba a concebir un nuevo tipo societario dentro de los contemplados por esa ley.

La inserción de la sociedad por acciones simplificada en la Ley General de Sociedades no debería concretarse considerándola un subtipo de la sociedad anónima como insinúa un sector de la doctrina (Vítolo, 2016), pues sus particularidades justifican tratarla como un nuevo tipo societario, una figura autónoma, intermedia entre la sociedad de responsabilidad limitada y la sociedad anónima, que comparte características con ambas ${ }^{2}$.

\footnotetext{
Sería incluso deseable que se aproveche la oportunidad que ofrece este proyecto para darle simplicidad y coherencia al ordenamiento jurídico societario argentino, eliminando de la grilla de tipos societarios las sociedades caídas en desuso, como por ejemplo la sociedad comandita simple, la sociedad comandita por acciones y la sociedad de capital e industria, y la que, con el ingreso de la sociedad por acciones simplificada, seguramente pasara a formar parte de la historia: la sociedad colectiva.
} 


\section{Quiénes pueden constituir una sociedad por acciones simplificada}

Volvamos al análisis de las particularidades del proyecto: en su artículo 34 dispone que la sociedad por acciones simplificada puede ser constituida por una o por varias personas, consiente así que las empresas sean unipersonales y lo hace sin imponerle las restricciones que prevé la Ley General de Sociedades para las otras sociedades unipersonales admitidas en nuestro ordenamiento: la sociedad anónima unipersonal que, al incluirla entre las enumeradas en el artículo 299 de la Ley General de Sociedades, se le impuso exigencias que se convirtieron en un valladar insuperable para su utilización por parte del pequeño y mediano empresario (Abdala, 2016a, 2016b; Marzorati, 2016).

El mencionado artículo 34 del proyecto establece además que la sociedad por acciones simplificada puede ser creada por personas humanas o jurídicas y nada dispone en relación con la posibilidad de que, quien funde una sociedad por acciones simplificada, sea también una sociedad por acciones simplificada o bien una sociedad anónima.

En ese orden de ideas, nada impide que una sociedad por acciones simplificada unipersonal o una sociedad anónima unipersonal constituya, como única socia, una sociedad por acciones simplificada ${ }^{3}$, siempre y cuando se respete lo dispuesto por el artículo 39 del proyecto que prevé que la sociedad por acciones simplificada, para constituir y mantener su carácter, no deberá estar comprendida en ninguno de los supuestos previstos en los incisos 1 (sociedades que hacen oferta pública de sus acciones), 3 (sociedades de economía mixta o de la sección VI), 4 (sociedades que realicen operaciones de capitalización, ahorro o en cualquier forma requieran dinero o valores al público con promesas de prestaciones o beneficios futuros) y 5 (sociedades que exploten concesiones o servicios públicos) del

3 Posibilidad que está vedada a la sociedad anónima en virtud de lo dispuesto en el artículo 1 in fine de la Ley General de Sociedades. artículo 299 de la Ley General de Sociedades, ni ser controlada o vinculada en más de un $30 \%$ por una sociedad de las que registra esa norma.

\section{La constitución e inscripción de la sociedad por acciones simplificada}

Como referimos en los acápites anteriores, uno de los principales objetivos del proyecto es que la constitución y la inscripción de sociedad por acciones simplificada sean fáciles, rápidas, desburocratizadas y de bajo costo.

Para lograr ese propósito se prevé, por ejemplo, que el contrato constitutivo pueda hacerse mediante un instrumento público o privado ${ }^{4}$ que la sociedad pueda erigirse por medios digitales, utilizando la firma digital; que la publicación de la constitución en el boletín oficial se haga solo por un día; que los registros públicos implementen procedimientos que otorguen celeridad a los trámites que realicen y, además, que creen un modelo o proforma de instrumento constitutivo que, cuando se emplee, les obligue a inscribir la sociedad en el plazo de 24 horas, contadas desde el día hábil siguiente al de la presentación de la documentación requerida; que lo bancos deban prever mecanismos para que estas sociedades abran cuentas en plazos breves, que la Administración Federal de Ingresos Públicos (AFIP) deba generar la constancia de obtención de la clave única de identificación tributaria (CUIT) en 24 horas, etc.

Si bien la intención de todas estas disposiciones es plausible, consideramos que es solo una expresión de deseos tras la que subyace el objetivo de darle al proyecto difusión e impacto periodístico.

Así por ejemplo, estimamos correcto que se permita constituir este tipo de sociedades por instrumento privado y no reviste mayor importancia la ampliación de quienes pueden certificar las firmas.

4 En este último caso, la firma pueda ser certificada en forma judicial, notarial, bancaria o por registro público competente. 
La idea de generar un modelo o proforma de estatuto es valiosa, pero hubiera sido mucho mejor que ese modelo lo prevea la propia ley o su decreto reglamentario (y no los registros públicos), para lograr así uniformidad de criterios en cuestiones en las que la diversidad nada aporta y mucho perjudica.

Es acertada la reducción a un día del plazo de publicidad de la constitución de la sociedad en el diario de publicaciones, aunque habría que reexaminar la real utilidad de este requisito que, en nuestra opinión, ha sido superado largamente en los tiempos modernos.

También consideramos correcta la idea de imponer a los registros públicos un plazo de 24 horas para inscribir las sociedades por acciones simplificadas que adopten el modelo o proforma que ellos mismos propongan, pues si bien ese término es fácilmente soslayable (el registro siempre puede argumentar que no se presentó toda la documentación necesaria), es una limitación a su autoridad -en muchos casos mal usada-y significa también una toma de posición por parte del legislador en la discusión doctrinaria referida a las reales facultades que tiene este organismo de control.

En cuanto a las disposiciones que apuntan a la utilización de medios digitales, son en nuestra opinión criticables, pues exceden el propósito y el objetivo de una ley que regula un nuevo tipo societario y, en realidad, son cuestiones que deberían ser objeto de regulación de una norma general sobre el uso de los medios digitales en los negocios y contratos.

Por lo demás, el proyecto determina que las entidades financieras deberán prever mecanismos que posibiliten a la sociedad por acciones simplificada la apertura de una cuenta en un plazo máximo a establecer por la reglamentación, requiriendo solo la presentación del instrumento constitutivo debidamente inscripto y la constancia de obtención de la CUIT y precisa además que la sociedad por acciones simplificada inscripta podrá obtener esa clave dentro de las 24 horas de presentado el trámite en la página web de la AFIP o ante cualquiera de sus agencias, sin necesidad de entregar prueba de su domicilio en el momento de inicio del trámite. Ambas previsiones normativas son criticables y deberían ser excluidas del proyecto, porque son cuestiones que competen al Banco Central de la República Argentina y a la AFIP respectivamente $y$, por ende, no deberían ser objeto de regulación en un proyecto de creación de un nuevo tipo societario como el que analizamos ${ }^{5}$.

\section{La responsabilidad de los socios}

De acuerdo con el artículo 34 del proyecto, la responsabilidad de los socios de la sociedad por acciones simplificada se circunscribe a la integración del capital oportunamente suscripto. Es decir que, en este novel tipo societario, los socios no responderán con sus patrimonios individuales por las obligaciones incumplidas por la sociedad, excepto, claro está, en los casos peculiares en los que se concrete la desestimación de la personalidad jurídica por aplicación de la teoría del disregard of the corporate entity.

En su parte final, el mencionado artículo 34 declara que esa responsabilidad es "sin perjuicio de la garantía a que se refiere el artículo 43" que, a su turno, ordena que los socios garanticen solidaria e ilimitadamente a los terceros la adecuada integración de los aportes.

Observamos que ese agregado es innecesario e impropio. Innecesario porque no se relaciona con la limitación de responsabilidad de los socios que prevé la norma y porque la obligación de integrar los aportes suscriptos deriva de la propia celebración del contrato societario, sin necesidad de una aclaración normativa. Pero además el agregado es impropio porque obviamente la responsabilidad del socio de integrar los aportes comprometidos es individual, con lo que mal puede ser calificada como solidaria e ilimitada.

5 Resulta hasta absurdo que el proyecto refiera en la parte final del inciso 1 del artículo 60 que las entidades financieras no estarán obligadas a otorgar crédito a la sociedad por acciones simplificada, pues se trata de una aclaración absolutamente impropia y profusa. 
Pero volvamos a la cuestión de la responsabilidad de los socios para enunciar que, en nuestra opinión, este aspecto de la norma es plausible, pues justamente la virtud de este tipo societario es ofrecer la oportunidad de formar sociedades unipersonales o pluripersonales, con bajos capitales en el momento fundacional.

Hay autores que critican este punto, pues piensan que la limitación de la responsabilidad de los socios solo es aceptable en aquellas sociedades que exigen una dotación de capital elevado y que cuentan con una idónea fiscalización interna y externa, pues -refieren-cuando la sociedad tiene capitales bajos y los socios responsabilidad limitada, quienes se vinculen con la sociedad y lo hagan desde una posición significativa de poder (proveedores, entidades financieras y otras empresas) podrán y sabrán tomar sus recaudos exigiendo avales y garantías a los administradores y accionistas para proteger sus créditos, y quienes quedarán desprotegidos serán los débiles (trabajadores, consumidores, acreedores involuntarios o incidentales), que no tendrán la posibilidad de buscar cobertura en garantías adicionales (Vítolo, 2010).

Discrepamos con esa tesis, pues entendemos que, en este tipo de sociedades, el capital social solo será bajo en la etapa fundacional y las obligaciones que contraerá la sociedad en ese periodo serán proporcionales a ese capital. Y en cuanto a los débiles (trabajadores, consumidores, acreedores involuntarios o incidentales), juzgamos que su tutela es una función que deben cumplir las instituciones del derecho de la seguridad social y no las del derecho societario, que además son impotentes para hacerlo, lo cual es fácilmente constatable con solo sopesar los ingentes perjuicios que con frecuencia ellos sufren en el sistema vigente ${ }^{6}$.

6 En efecto, la tutela de los trabajadores podría ser sencillamente lograda reemplazando el nefasto sistema de indemnizaciones que prevé nuestra legislación laboral por un sistema de seguro de desempleo, y la protección de los consumidores y de los acreedores incidentales puede también alcanzarse mediante la efectiva obligatoriedad de diversos seguros de responsabilidad civil. Véase al respecto Abdala (2000).

\section{El capital social: mínimos y máximos previstos}

El proyecto prevé en su artículo 40 que el capital social inicial necesario para constituir una sociedad por acciones simplificada no podrá ser inferior a una suma equivalente a dos veces un salario mínimo vital y móvil ${ }^{7}$.

Como puede observarse, el capital social mínimo es sustancialmente inferior al exigido a la sociedad anónima y ello hace que la sociedad por acciones simplificada se asemeje en ese aspecto a la sociedad de responsabilidad limitada, que no requiere un monto mínimo de capital fundacional.

La decisión de fijar un capital mínimo tan bajo es, en definitiva, tomar partida en la discusión doctrinaria sobre la importancia y las funciones del capital social y coincidir con quienes afirmamos que, en los tiempos actuales, su cuantía perdió por completo relevancia ${ }^{8}$.

Ahora bien, para evitar que el capital mínimo exigido para constituir una sociedad por acciones simplificada se deprecie por efecto de la inflación, el proyecto optó por no expresar una suma de dinero ni delegar esa tarea o responsabilidad (apartándose de lo dispuesto por el artículo 186 de la Ley General de Sociedades que dicta que el capital mínimo de la sociedad anónima sea determinado periódicamente por el Poder Ejecutivo Nacional), quizá consciente de la infausta experiencia reciente, en donde se omitió modificar ese monto mínimo durante un largo periodo.

En efecto, en lugar de imponer la cuantía del capital social, el proyecto se inclinó por disponer

$7 \quad$ Desde el 1 de enero de 2017 el salario mínimo vital y móvil es de \$ 8060, con lo que el capital mínimo de una sociedad por acciones simplificada será de $\$ 16.120$ de acuerdo con la resolución 2/16 del Consejo del Salario Mínimo Vital y Móvil.

8 Las garantías del crédito son independientes de la forma societaria, porque dependen del patrimonio y de las seguridades que ofrece a los acreedores su o sus titulares. El que no tiene bienes y sus ingresos solo le permiten sobrevivir, no es sujeto de crédito, salvo en mercados secundarios (Marzorati, 2015). 
que el mismo sería una suma que resulta de multiplicar por dos el salario mínimo vital y móvil que, en la experiencia histórica reciente y por distintas razones, es actualizado con periodicidad.

Por nuestra parte conceptuamos que esta manera de lograr un sistema de revalorización de una cifra monetaria es aceptable, y no nos parece admisible ni la crítica ni la propuesta de algunos autores, que reprochan que ese monto se vincule con el salario mínimo y proponen que se lo haga con la obligación de pago mensual de los contribuyentes que tengan la categoría de monotributistas (Vítolo, 2016).

Hechas esas apreciaciones en relación con el capital mínimo previsto en el proyecto, corresponde ahora que aludamos al capital máximo, para destacar que, contrario a lo que pudiera esperarse, la norma que analizamos no prevé un capital social máximo para este tipo de sociedades.

El soslayo es censurable, pues tratándose de una herramienta que tiene como principal destinatario al pequeño y mediano empresario, es erróneo omitir la cuantía del capital social máximo que la misma pueda tener, para evitar de esa forma que se aproveche este tipo societario para canalizar emprendimientos económicos de magnitud.

Para colmo de males, como estas sociedades son un tipo societario diferente a los previstos por la Ley General de Sociedades, la posibilidad de que la sociedad por acciones simplificada que alcance o supere un capital social de $\$ 10.000 .000$ sea incluida entre las sociedades sometidas a un control estatal permanente previsto en el artículo 299 de la Ley General de Sociedades será por lo menos discutible, mucho más si se tiene en cuenta que el artículo 39 del proyecto, que prevé los supuestos en los que la sociedad por acciones simplificada debe transformarse en uno de los tipos previstos en la Ley General de Sociedades, ciñe esa obligación a los casos que se consagran en los incisos 1 (sociedades que hacen oferta pública de sus acciones), 3 (sociedades de economía mixta o de la sección VI), 4 (sociedades que realicen operaciones de capitalización, ahorro o en cualquier forma requieran dinero o valores al público con promesas de prestaciones o beneficios futuros) y 5 (sociedades que exploten concesiones o servicios públicos) del artículo 299 de la Ley General de Sociedades y a los supuestos en que la sociedad por acciones simplificada esté controlada o vinculada en más de un 30 \% del capital por una sociedad comprendida en esa norma, omitiendo claramente el inciso 2 de la disposición, que refiere a las sociedades que alcancen o superen un capital social de $\$ 10.000 .000$.

Creemos entonces que debe modificarse este aspecto del proyecto y marcar un capital social máximo que impida constituir una sociedad por acciones simplificada con un capital social por encima de una cifra determinada y que, cuando ello ocurra, les obligue a transformarse en alguno de los tipos previstos en la Ley General de Sociedades $y$, si se corresponde, la incluya entre las sociedades con fiscalización estatal permanente citadas en el artículo 299 de la Ley General de Sociedades.

\section{Los aportes de los socios}

El artículo 42 del proyecto establece que los aportes que realicen los socios de una sociedad por acciones simplificada pueden consistir en bienes dinerarios, bienes no dinerarios y prestaciones accesorias.

Semejante a lo dispuesto por los artículos 149 y 187 de la Ley General de Sociedades para la sociedad de responsabilidad limitada y para la sociedad anónima respectivamente, se prevé que, cuando los aportes fueran dinerarios, ellos deben integrarse en un mínimo del $25 \%$ en el momento de la suscripción del capital y puede diferirse el saldo hasta un plazo máximo de dos años.

Los aportes en bienes no dinerarios deben ser integrados totalmente en el momento de la suscripción y, como ocurre en la sociedad de responsabilidad limitada y en la sociedad anónima (artículos 51 y 149 de la Ley General de 
Sociedades), los socios deben acordar el valor de esos bienes e indicar en el instrumento constitutivo los antecedentes justificativos de esa valuación.

Finalmente, el proyecto autoriza a los socios a aportar "prestaciones accesorias" y aclara que ellas son prestaciones de servicios realizadas o a realizar en el futuro por los propios socios, por los administradores o por proveedores.

Todas estas disposiciones y, en definitiva, la minuciosa regulación que efectúa el proyecto de los distintos tipos de aportes que se autoriza a los socios a hacer para integrar el capital social suscripto son, en nuestra opinión, superfluas y criticables.

Es tan bajo el capital social mínimo con el que puede constituirse una sociedad por acciones simplificada que en modo alguno se justifica ofrecer a los socios la alternativa de diferir la integración cuando el aporte fuera dinerario y, mucho más, la posibilidad de integrarlo en especie o en prestaciones accesorias.

Estas previsiones boicotean el objetivo de simplicidad que el propio proyecto manifiesta perseguir y lo convierte en este punto en un sistema innecesariamente complejo y alambicado, que puede estar justificado cuando la constitución de la sociedad presupone desembolsar elevadas sumas de dinero, pero que resulta inane en una sociedad simplificada, que puede válidamente constituirse con un capital social mínimo de apenas \$16.000, el equivalente a USD 1000.

En ese orden de ideas, creemos que es vital modificar este aspecto del proyecto y exigir que la totalidad del capital suscripto sea integrada al momento de celebrarse el contrato constitutivo, autorizándose a hacerlo únicamente en dinero en efectivo. Y si se considera que, en este caso, el desembolso inicial que tienen que hacer los socios es elevado, el problema se resuelve con facilidad, disminuyendo la exigencia de capital mínimo, ya que lo mismo da requerir a una sociedad un capital inicial mínimo equivalente a uno, o a dos salarios mínimo (\$16.000 o \$
8000), pues en ambos casos la cifra es exigua y hasta paupérrima.

\section{Las acciones representativas del capital}

Recordemos que la estructura de la sociedad por acciones simplificada guarda similitud con la de la sociedad de responsabilidad limitada (que es la forma jurídica que resulta más afín), pero incorpora como novedad que las partes alícuotas en las que se divide el capital se denominan acciones, como ocurre en la sociedad anónima (artículo 40 del proyecto).

En este punto el proyecto acusa una total falta de coherencia, pues si el capital se divide en partes alícuotas, lo lógico hubiera sido que ellas se denominen cuotas o cuota-partes ${ }^{9}$, y no que se las llame acciones, como lo hace de manera improcedente el proyecto, sino a riesgo de convertir a la sociedad por acciones simplificada en una suerte de cruza o mestizaje impropio entre la sociedad de responsabilidad limitada y la sociedad anónima.

Pero no solo es reprochable el proyecto en este punto por el nombre que le da a las alícuotas en que está dividido el capital, sino también porque, una vez más, se aparta de la simplicidad que declamaba perseguir y autoriza, en los artículos 46 y 47, que la sociedad por acciones simplificada emita distintos tipos de acciones.

En efecto, el artículo 46 del proyecto expone la posibilidad de que estas sociedades emitan acciones nominativas no endosables, ordinarias o preferidas y acciones escriturales, y luego el artículo 47 se detiene en los derechos políticos y económicos que puede reconocérsele a las distintas clases de acciones y a las soluciones para los casos en los que no se emitan los títulos representativos.

A nuestro juicio estas normas son inconvenientes e innecesarias: inconvenientes porque, si el objetivo

Como ocurre con las cuotas de la sociedad de responsabilidad limitada según el artículo 146 de la Ley General de Sociedades. 
del proyecto es ofrecer a los emprendedores una estructura societaria simple y desburocratizada, pensada más en el empresario unipersonal que en la sociedad con multiplicidad de socios, no tiene sentido alguno prever tantas alternativas $y$ posibilidades en lo que respecta a las acciones que pueden emitirse; e innecesaria porque, en lugar de esta minuciosa regulación, hubiera bastado con la remisión a las disposiciones de la Ley General de Sociedades que regulan la emisión de acciones en la sociedad anónima.

\section{Organización jurídica interna}

El capítulo IV del proyecto se intitula "Organización de la sociedad", por lo que era de esperarse que reglamentara de manera detallada y sistemática los diferentes órganos que forman la sociedad por acciones simplificada.

La espera es vana porque, contrario a lo previsto, ese capítulo muestra una absoluta falta de coherencia, de sistematicidad y de método, lo que termina convirtiéndolo en un verdadero "menjunje", en el que se legislan cuestiones diversas y dispares ${ }^{10}$.

A poco de andar advertimos el primer yerro: el proyecto destina tres artículos de ese capítulo para reglar el órgano de administración de la sociedad por acciones simplificada (y lo hace de forma innecesariamente compleja y copiosa) y solo uno para hacer lo propio con el órgano de gobierno y con el de fiscalización (también de inadecuada manera).

Por otro lado, el artículo 49 del proyecto preceptúa que los socios determinarán la estructura orgánica de la sociedad y la reglas que regirán el funcionamiento de sus órganos sociales. Hasta este punto, pareciera que el legislador se propone dar amplias libertades para que los socios estructuren como

10 El artículo 49 apunta a la "Organización jurídica interna", el artículo 50 al "Órgano de administración", el artículo 51 a las "Funciones del administrador", el artículo 52 a los "Deberes y obligaciones de los administradores" y el artículo 53 al "Órgano de Gobierno. Órgano de fiscalización opcional”. les plazca la organización jurídica interna de la sociedad, pero a renglón seguido retrocede, e impone la obligación de contar con los "órganos eje", que son -en definitiva-los identificados por la doctrina en todo tipo de sociedad.

Para colmo de males, el proyecto hace una minuciosa regulación de ciertos aspectos de cada uno de los órganos, que consideramos sin utilidad, pues el mismo artículo 49 del proyecto dispone que, en las cuestiones referidas al funcionamiento de los órganos de la sociedad por acciones simplificada, se aplicarán en forma supletoria las normas que regulan la sociedad de responsabilidad limitada y las disposiciones generales de la Ley General de Sociedades.

En los próximos acápites analizaremos las regulaciones que hace el proyecto de cada uno de los órganos de la sociedad por acciones simplificada.

\section{El órgano de administración}

Comenzaremos con el órgano de administración y lo haremos destacando que, en su artículo 50, el proyecto establece que la administración y representación de la sociedad por acciones simplificada estarán a cargo de una o más personas y aclara que deberá ser "humana", cerrando la posibilidad de que ella esté en cabeza de una persona jurídica, como ocurre en otras alternativas de organización para generar patrimonios de afectación y canalizar actividades empresariales, como lo son los fideicomisos de administración, que puede estar gerenciados por un administrador fiduciario, que puede ser una persona física o jurídica.

Como se observa, el precitado artículo no eligió una denominación especial para referirse a los administradores de la sociedad por acciones simplificada (como lo hace la Ley General de Sociedades, que llama directorio al órgano de administración de las sociedades anónimas y gerencia al de las sociedades de responsabilidad limitada), lo cual nos obliga a usar la genérica denominación "administradores societarios" para aludir a ellos. 
El proyecto prevé en relación con esos administradores diversas disposiciones innecesarias y sobreabundantes: que ellos pueden o no ser socios de la sociedad por acciones simplificada; que pueden ser designados por un plazo determinado o indeterminado; que se los puede elegir en el instrumento constitutivo o posteriormente; que su designación y cese deben inscribirse en el registro público, que en los casos en los que el órgano de administración fuere plural, el estatuto podrá instituir las funciones de cada administrador o disponer que estas se ejerzan de forma conjunta o colegiada, etc.

Por otro lado, del mismo modo que ocurre en la sociedad anónima, y a fin de evitar situaciones de acefalía del órgano de administración societario, el proyecto exige designar por lo menos un administrador suplente, en caso que se prescinda del órgano de fiscalización.

Para nosotros, por las características peculiares de este tipo societario y por la simplicidad buscada por el legislador para sus estructuras, el problema de la eventual acefalía del órgano de administración podría haberse resuelto de mejor manera estableciendo que, en esos casos, los socios de la sociedad por acciones simplificada pasan a ocupar inmediatamente el cargo de administradores de la sociedad. Así se logra el objetivo perseguido por la ley, se reduce la estructura de la sociedad y se esquiva el lastre que significa para el pequeño $y$ mediano empresario tener que elegir entre dos opciones que le pueden resultar excesivas para su negocio, esto es, designar un síndico o elegir un administrador suplente.

El artículo 51 del proyecto se superpone al artículo 50 y repite que la representación legal de la sociedad por acciones simplificada estará a cargo de una persona humana, designada en el instrumento constitutivo o con posterioridad, por la reunión de socios o el socio único, y luego precisa, con sobreabundancia, que ese representante legal podrá celebrar y ejecutar todos los actos y contratos comprendidos en el objeto social o que se vinculen directa o indirectamente con el mismo.
El artículo 51 del proyecto se detiene en la cuestión del domicilio de los administradores societarios de la sociedad por acciones simplificada y decreta que, al menos uno de sus miembros, deberá tener domicilio real en la Argentina, y que los miembros extranjeros deberán contar con una clave de identificación, designar representante y fijar un domicilio en Argentina. Todas estas exigencias son incorrectas y no alcanzamos a entender las razones para diferenciar entre administradores societarios que tengan su domicilio en Argentina y los que lo tengan en el extranjero ni, mucho menos, las imposiciones y exacciones adicionales a estos últimos. Creemos primordial eliminar estos requisitos del proyecto, pues mientras el administrador societario tenga un domicilio constituido en el lugar donde está la sede social, todas las otras previsiones normativas son innecesarias y erróneas.

También se refiere el proyecto a las reuniones del órgano de administración y consagra que la citación y la información sobre el temario podrán realizarse por medios electrónicos, sin aclarar cómo se hará para demostrar una y otra circunstancia, soslayando la falta de previsiones al respecto de la que adolecen los códigos adjetivos de nuestro país.

El artículo 52 del proyecto aborda el asunto de los deberes de los administradores de la sociedad por acciones simplificada y establece que ellos tienen iguales obligaciones y responsabilidades que los gerentes de la sociedad de responsabilidad limitada.

A renglón seguido, y con completa falta de método, alude al órgano de fiscalización y dispone que le son aplicables "las normas previstas en la mencionada ley, en lo pertinente", lo que convierte a ese artículo en una norma inútil, pues la Ley General de Sociedades no estima un régimen especial que determine las obligaciones de los gerentes de la sociedad de responsabilidad limitada ni, mucho menos, que se refiera a las responsabilidades que pudieran derivar del incumplimiento de esos deberes. Por el con- 
trario, las pocas y dispersas disposiciones que son útiles a la hora de juzgar la responsabilidad de los administradores de sociedades están en la parte general de la ley o entre las normas que regulan la actividad de los directores de la sociedad anónima y se aplican por analogía a los demás administradores societarios. Por todo ello, debe modificarse esta parte del proyecto y disponer que los administradores societarios de la sociedad por acciones simplificada tienen las mismas obligaciones que se reportan en la Ley General de Sociedades para los administradores de los distintos tipos de sociedades.

Por último, el artículo 52 del proyecto se detiene en los administradores fácticos y afirma que quienes, sin ser administradores, intervinieren en una actividad positiva de gestión, administración o dirección de la sociedad, incurrirán en las mismas responsabilidades aplicables a los administradores y su responsabilidad se extenderá a los actos en los que hubieren participado cuando su actuación administrativa fuere habitual. Esta norma es del todo superflua y por ello debería suprimirse del proyecto.

\section{El órgano de gobierno societario}

El artículo 53 del proyecto prevé que la reunión de socios es el órgano de gobierno de la sociedad por acciones simplificada y regula, con minuciosidad múltiples cuestiones sobre cómo debe ejecutarse e instrumentarse.

Ese artículo contempla la posibilidad de que esas reuniones puedan concretarse fuera de la sede social o "a distancia", utilizando medios que permitan a los participantes comunicarse simultáneamente entre ellos ${ }^{11}$, y determina que, en esos casos, el acta que las instrumenta deberá indicar el modo de comunicación empleada (deben conservarse las constancias de acuerdo con el medio usado: la grabación en caso de ser telefónica, el video en caso de ser una teleconferencia, etc.) y deberá ser firmada por el

11 En realidad, el proyecto no autoriza expresamente estas reuniones, sino que dispone que podrá hacerlo el estatuto. administrador o representante $e^{12}$ que estuviera presente en la sede social y, si no estuviera ninguno, por el representante legall ${ }^{13}$.

La norma es poco feliz y su redacción colmada de errores. Si el objetivo es autorizar las reuniones de socios a distancia, sería mucho más apropiado reformar la parte general de la Ley General de Sociedades e introducir en ella una norma que las permita no solo en la sociedad por acciones simplificada, sino en todos los tipos societarios.

Ello es así porque nuestro ordenamiento jurídico societario no requiere un nuevo tipo de sociedad que tenga un alto grado de modernidad, desacoplada con las estructuras antiguas previstas para los otros tipos societarios, sino una reforma integral de la parte general de la ley, que impregne de esa modernidad a todas las sociedades. Incluso más, sería loable dictar una ley que modernice en este aspecto el Código Civil y Comercial, y reglamente las reuniones a distancia de los cuerpos colegiados de todas las personas jurídicas.

Pero regresemos a lo que dispone el proyecto en cuanto a las reuniones del órgano de gobierno de la sociedad por acciones simplificada: el sistema que prevé la norma es ágil, moderno y sumamente efectivo cuando las relaciones intrasocietarias transitan en los carriles de armonía, confianza y concordia, pero muy vulnerable en los casos en los que existe desconfianza y, ni qué decir, cuando hay entuertos.

Ello es así porque en las hipótesis de conflicto, existiría un claro desacople entre la modernidad del sistema para realizar las reuniones del órgano de administración previsto por el proyecto y

12 El proyecto no aclara si se refiere a un representante de la sociedad, a un representante del administrador societario o a un representante de el o los socios.

13 Tampoco explica el proyecto en qué difiere el representante que se menciona en esta parte de la norma con el citado en el párrafo anterior, manteniéndose la duda sobre si se alude a un representante legal de la sociedad, del administrador o de los socios. 
la antigüedad de los sistemas procesales para demostrar en un juicio la existencia, desarrollo y contenido de las mismas.

Ahora bien, además de las analizadas cuestiones sobre las reuniones a distancia, el artículo $53 \mathrm{del}$ proyecto apunta, en nuestra opinión sin utilidad aparente, a los casos en los que la sociedad por acciones simplificada tuviera un socio único y establece que, en esos supuestos, las resoluciones del órgano de gobierno serán adoptadas por ese socio, dejando constancia de ellas en actas asentadas en los libros de la sociedad.

También creemos que es excesiva la parte final de dicho artículo 53 para quien toda comunicación o citación a los socios deberá dirigirse al domicilio constituido en el instrumento constitutivo si no se hubiera notificado su cambio al órgano de administración y el artículo 49 del proyecto, que regula la reunión de los administradores y establece que pueden autoconvocarse sin citación previa, luego, con absoluta falta de método y casi "de pasada", dispone que igual regla se aplica para las reuniones de socios, precisando que en ese caso las resoluciones del órgano de gobierno que se tomen serán válidas si asisten los accionistas que representen el $100 \%$ del capital social y el orden del día es aprobado por unanimidad.

Por último, el artículo 53 del proyecto transcribe el artículo 159 de la Ley General de Sociedades y otorga la posibilidad de llegar a una resolución social del órgano de gobierno societario sin hacer una real reunión de socios, mediante el procedimiento "de recolección de votos" en el que el órgano de administración efectúa una consulta simultánea a los socios sobre cuestiones que son de competencia del órgano de gobierno, los socios son emplazados a contestar esa consulta en el plazo de diez días y, vencido el mismo, el órgano de administración contabiliza los votos recibidos y considera adoptada o no la decisión del órgano de gobierno ${ }^{14}$. Obviamente que la

14 Tanto la consulta a los socios como sus respuestas deben ser hechas de un modo fehaciente, mediante cualquier norma es inútil y hubiera sido suficiente una simple remisión en lugar de transcribir el artículo que aborda la cuestión en la Ley General de Sociedades.

\section{El órgano de fiscalización}

En el mismo artículo que regula el órgano de gobierno (el analizado artículo 53) el proyecto menciona al órgano de fiscalización, y lo hace en forma tangencial y de manera totalmente insuficiente, reseñando en el título de esa norma: "órgano de fiscalización opcional".

Como puede observarse el método es criticable porque, en un único artículo, el proyecto aborda dos cuestiones tan importantes como lo son el órgano de gobierno y el órgano de fiscalización societaria, tópicos que sería mucho más conveniente que tuvieran normas separadas, exclusivas para cada uno de ellos.

Por si fuera poco, la indicación que se hace en ese artículo al órgano de fiscalización se reduce y circunscribe a decir en el título que será "opcional", lo que entendemos que, en rigor técnico, es impropio, pues en toda estructura societaria existe un órgano de fiscalización $y$, lo que puede ser opcional, es que las tareas encomendadas a ese órgano las lleven a cabo los propios socios, un síndico o un consejo de vigilancia.

Ahora bien, a pesar de los defectos de redacción y método señalados en los párrafos anteriores, lo cierto es que, de una interpretación integral del proyecto que examinamos, surge que la sociedad por acciones simplificada puede prever en el estatuto que su fiscalización esté a cargo de un síndico, de un consejo de vigilancia o de sus socios, decisión que consideramos válida, por todas las ventajas que conlleva la reducción de la estructura de organización del ente $e^{15}$.

medio o procedimiento que garantice su autenticidad, como por ejemplo una carta documento, una carta con imposición notarial de contenido, una notificación notarial, una nota con firma certificada, etc.

15 En contra Vítolo (2016), quien opina que la lógica señala 


\section{La transformación}

El artículo 61 del proyecto asegura que cualquier sociedad constituida conforme a la Ley General de Sociedades puede transformarse en una sociedad por acciones simplificada, e impone a los registros públicos la obligación de reglamentar los procedimientos que deben observarse para concretar esa transformación.

La norma es plausible pues, por los beneficios que ofrece la sociedad por acciones simplificada, es de esperar que muchas sociedades tengan interés en transformarse y optar por este nuevo tipo societario. Sin embargo, es un equívoco que la regulación del procedimiento de transformación se delegue en los diferentes registros públicos, razón por la cual consideramos que sería necesario cambiar en este punto el proyecto y prever un procedimiento de transformación simple, sencillo y sin innecesarias regulaciones casuísticas, o bien encomendar esa tarea a la reglamentación de la norma que a la postre haga el Poder Ejecutivo Nacional.

Por lo demás, el artículo 39 del proyecto contempla el camino inverso, pues contiene lo que ocurre cuando una sociedad por acciones simplificada, con posterioridad a su constitución, resulta comprendida en alguno de los supuestos que aparecen en los incisos del artículo 299 de la Ley General de Sociedades y aquel donde la sociedad por acciones simplificada esté controlada o vinculada en más de un 30 $\%$ del capital por una sociedad comprendida en esa norma, es decir, sometida al contralor estatal permanente.

En ese supuesto, la sociedad por acciones simplificada deberá transformarse en alguno de los tipos contemplados en la Ley General de Sociedades e inscribir esa transformación en el registro público correspondiente en un plazo no mayor a los seis meses, instituyéndose como sanción, en caso de que los socios no lleven a cabo la

que la sociedad por acciones simplificada debe tener un órgano de fiscalización, en razón de tratarse de una sociedad que incluso puede ser unipersonal. transformación en dicho plazo, la modificación de su régimen de responsabilidad que, a partir de esa inobservancia, será solidaria, ilimitada y subsidiaria.

\section{Conclusiones}

En líneas generales creemos que el objetivo del proyecto de ley de creación de las sociedades por acciones simplificadas que analizamos es valioso, pero el mismo acusa una pluralidad de defectos, imprecisiones y errores que ameritan su revisión, sobre todo porque la promesa de simplicidad que motiva y justifica la creación del nuevo tipo societario es incumplida por el propio proyecto, que propone una regulación alambicada, compleja y en muchos casos sobreabundante.

La primera crítica que corresponde hacer al proyecto es de orden metodológico, pues la incorporación de un nuevo tipo societario no debería concretarse sancionando un cuerpo normativo independiente, sino modificando la Ley General de Sociedades y aprovechando esa oportunidad para darle simplicidad y coherencia al ordenamiento societario argentino, eliminando de la grilla de tipos a las sociedades caídas en desuso, como las comanditas simples, las comanditas por acciones y las de capital e industria y las que, con la incorporación de la sociedad por acciones simplificada pasarán a formar parte de la historia como las sociedades colectivas.

El proyecto dispone que la sociedad por acciones simplificada puede ser constituida por una o por varias personas, permitiendo de esa manera que esos emprendimientos empresariales sean unipersonales y sin las restricciones que tiene la sociedad anónima unipersonal. Además, el proyecto establece que la novel sociedad puede ser constituida por personas humanas o jurídicas y nada dispone en relación con la posibilidad de que, quien la constituya, sea también una sociedad por acciones simplificada o una sociedad anónima, plural o unipersonal.

Se previeron diversas normas que tienen como objetivo que la constitución y la inscripción del 
nuevo tipo societario sean fáciles, rápidas, desburocratizadas y de bajo costo. La intención de esas disposiciones es elogiable, pero muchas de ellas son criticables y la mayoría solo representa una expresión de deseos tras la que subyace el propósito de darle al proyecto difusión e impacto periodístico.

Consideramos acertada la decisión de disponer que en la sociedad por acciones simplificada la responsabilidad de los socios se circunscriba a la integración del capital oportunamente suscripto, a pesar de la crítica de un sector de la doctrina que se preocupa por la supuesta desprotección de los trabajadores, los consumidores y los acreedores involuntarios o incidentales, pues entendemos que esa tutela no es una función ni tarea del derecho societario que, además, demostró su impotencia para lograrla.

Se prevé que el capital social inicial necesario para constituir una sociedad por acciones simplificada no podrá ser inferior a una suma equivalente a dos veces un salario mínimo vital y móvil lo que implica, en definitiva, tomar partida en la discusión doctrinaria referida a la importancia del capital y coincidir con quienes afirmamos que su cuantía perdió por completo relevancia.

Se le reprocha al proyecto que no estipule un capital máximo para este tipo de sociedades, pues tratándose de una herramienta que tiene como principal destinatario al pequeño y mediano empresario, resulta erróneo omitir el capital máximo que ellas pueden tener, para evitar así que se utilice este tipo societario para canalizar emprendimientos económicos de magnitud.

La minuciosa regulación que hace el proyecto de los distintos tipos de aportes que se autoriza a los socios a realizar para integrar el capital social es innecesaria, pues es tan bajo el capital mínimo con el que puede constituirse una sociedad por acciones simplificada, que no se justifica ofrecer a los socios la posibilidad de diferir su integración o de hacerlo de una forma diferente a un desembolso dinerario.
El proyecto dicta que el capital de la sociedad por acciones simplificada se divida en partes alícuotas y las denomina acciones, lo que resulta incoherente, pues lo lógico hubiera sido que se llamaran cuotas o cuota-partes. Pero no solo es criticable el nombre que se le dio a las alícuotas, sino también que se autorice a la sociedad por acciones simplificada a emitir distintos tipos de acciones, lo que juzgamos totalmente inconveniente e innecesario.

Las disposiciones del proyecto en relación con el órgano de administración, referidas a las situaciones de acefalía, a las cuestiones del domicilio, a las reuniones del órgano, a los deberes y responsabilidades de los administradores, etc., son, en la mayoría de los casos innecesarias y copiosas, y deben por ello ser revisadas o suprimidas.

El proyecto prevé que la reunión de socios es el órgano de gobierno de la sociedad por acciones simplificada, regula con detalle cómo debe realizarse e instrumentarse y consagra un procedimiento para concretarla "a distancia", que es ágil, moderno y bastante efectivo cuando las relaciones intrasocietarias son armoniosas, pero muy vulnerable cuando existe desconfianza o conflictos, por el evidente desacople entre la modernidad de ese procedimiento y la antigüedad de los sistemas procesales vigentes.

En el mismo artículo que regula el órgano de gobierno el proyecto trata sobre el órgano de fiscalización, y lo hace en forma tangencial $e$ insuficiente, solo para mencionar, casi al pasar, que el mismo será "opcional", lo que entendemos que es impropio e incorrecto, a pesar de lo cual consideramos válido que se autorice que, en estas sociedades, sean los socios quienes decidan en manos de quién estará su fiscalización.

El proyecto admite que cualquier sociedad constituida conforme a la Ley General de Sociedades pueda transformarse en una sociedad por acciones simplificada e impone a los registros la obligación de reglamentar los procedimientos para hacerlo. La norma es plausible porque es de esperar que muchas sociedades opten por este nuevo tipo, 
pero es criticable que el procedimiento se delegue en los registros.

El proyecto contempla el camino inverso y prevé lo que ocurre cuando una sociedad por acciones simplificada, con posterioridad a su constitución, resulta comprendida en alguno de los supuestos que se registran en los incisos 1, 3, 4 y 5 del artículo 299 de la Ley General de Sociedades o controlada o vinculada en más de un $30 \%$ del capital por una sociedad sometida al contralor estatal permanente, en cuyo caso los socios están obligados a transformarla en alguno de los tipos que caracteriza la Ley General de Sociedades, bajo apercibimiento de que se modifique su régimen de responsabilidad.

\section{Referencias}

Abdala, M. (2000). El reemplazo de la reparación fundada en la responsabilidad civil por el resarcimiento a cargo de un sistema de seguros como solución a la problemática de los daños ocasionados con automotores. Revista de Responsabilidad Civil y Seguros, 2(5), 199-210.
Abdala, M. (2016a). El régimen de las sociedades anónimas unipersonales en la ley general de sociedades. Jurisprudencia Argentina, IV, 1-4.

Abdala, M. (2016b). Importante reforma al régimen de las sociedades anónimas unipersonales. Jurisprudencia Argentina, VI, 1-3.

Marzorati, O. (2015). Algunas consideraciones sobre la sociedad unipersonal y la empresa individual de responsabilidad limitada. Revista Foro Derecho Mercantil, 49(octubre-diciembre), 11-59.

Marzorati, O. (2016). La Sociedad Anónima Simplificada. ¿Será una realidad? Revista Jurídica Argentina La Ley, 1(12), 1-3.

Vítolo, D. (2010). Aportes, capital social e infracapitalización en las sociedades comerciales. Buenos Aires: Rubinzal Culzoni.

Vítolo, D. (2016). La sociedad anónima simplificada (sociedad por acciones simplificada). Revista Jurídica Argentina La Ley, 5(10), 1-3. 